\title{
A Simulation Method for Measuring Building Physics Properties
}

\author{
Ljubomir Jankovic \\ Zero Carbon Lab, School of Creative Arts, University of Hertfordshire, Hatfield, UK.
}

\begin{abstract}
Designing building energy performance with confidence requires accurate information on the properties of building materials and on assemblies of these materials. However, thermal properties of the building in use are rarely compared to manufacturers' specifications. The approach reported in this paper determines building thermal properties using simulations of dynamic heating tests. It replaces the need for physical tests with the actual buildings, by conducting these tests with calibrated simulation models using data from energy performance monitoring of that building during its normal operation. The resultant method represents a tool for establishing physics properties of buildings in use before and after retrofit, and facilitates quality control of retrofit projects. The results pinpoint major discrepancies between theoretical and actual thermal properties before and after the retrofit, giving practical guidance for safety margins in relation to technical specifications of building material properties and re-evaluation of corresponding technical specifications.
\end{abstract}

\section{Introduction}

The research introduced here seeks to answer a practical question on how to assess whether U-values of the components of external envelope are equal to or higher than those in manufacturers' specifications. Designing building energy performance with confidence requires accurate information on the properties of building materials and on assemblies of these materials. This includes properties of thermal insulation and masonry materials, as well as glazing and cladding assemblies. But how can we find out if these properties are different from manufacturers' specifications, once the building is built or retrofitted? Would answers be available from research into inverse modelling or model calibration?

Yuna Zhang et al. (2015) worked on comparing inverse modelling approaches for predicting building energy performance. They reviewed a change-point regression model, a Gaussian process regression model, a Gaussian mixture regression model and an Artificial neural network model. Whilst some of these models exhibited lower RMSE in comparison with the others (Gaussian mixture regression model), and some were better at capturing nonlinear relationships, such as Artificial neural network model, establishing building physics parameters was outside of the scope of their research. Ruiz et al. (2016) worked on a genetic algorithm for building envelope calibration. In addition to achieving a calibrated model and comparing it to four different calibration standards, they outline several possible uses of this research, including model based control, commissioning, and most relevantly for the subject of this article "to take into account thermal energy storage in buildings". Despite of this statement, no attempt was made to quantify the effect of thermal energy storage property of the building. Rezaee et al. (2019) used linear inverse modelling for performance based design exploration, and established a relationship between a range of design parameters and preferred thermal performance, however no attempt to establish building physics parameters was made. (Abushakra, 1997) used Stepwise Multiple Linear Regression, Fourier series, and Monte Carlo simulation to create an inverse model of a building based on sort term measurements and predict its long term performance before and after retrofit, with prediction errors between $4 \%$ and $23 \%$. As in the previous cases, establishing building physics parameters was outside of the scope of this work.

There are two tests that can help to establish the combined effect of material properties on building performance: a co-heating test (Jankovic, 2017, p. 251) and a dynamic heating test (Jankovic, 2017, p. 259). The former involves the use of portable electric heaters and measures the overall transmittance-area product when the building reaches equilibrium after the heaters have been switched on. The latter measures the building time constant, the overall thermal capacitance, and the overall transmittance-area product while the building goes through dynamic change of temperature after the heaters have been switched on. Both tests require the building to be unoccupied during one to two weeks, with stable weather conditions throughout that period. This is impractical for several reasons: the tests can only be conducted in cold weather, and this may not coincide with the completion of retrofit work; the occupants need to be provided with alternative accommodation during the test period; the weather conditions may become unstable and influence the test results, causing an extension of the test period; and dynamic heating can cause cracks at interfaces of different building materials and different rates of thermal expansion, due to higher than usual internal temperatures. The approach reported in this paper replaces the need for physical tests with the actual buildings, by conducting these tests with calibrated 
simulation models using data from energy performance monitoring of that building during its normal operation.

The research described here was carried out on a residential building, shown in Figure 1, that had undergone deep energy retrofit in a project called Retrofit Plus (Jankovic \& Basurra, 2016).

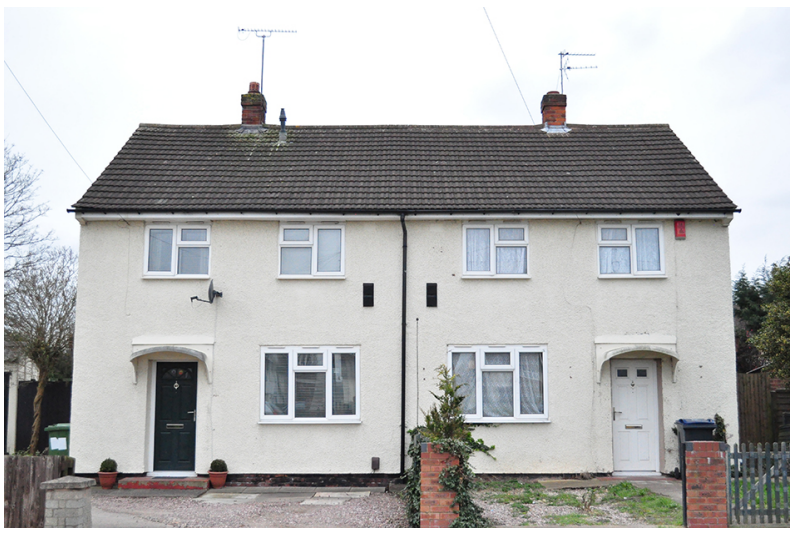

a) before retrofit

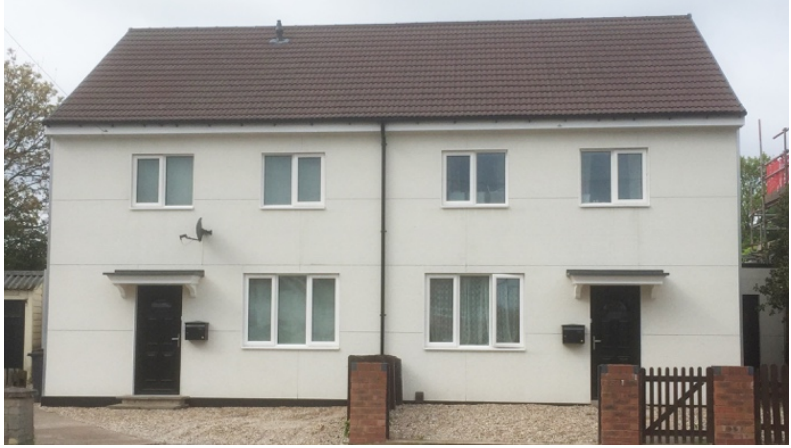

b) After retrofit

Figure 1: Residential building used as evidence base.

This residential building consisted of two semi-detached houses, attached through a party wall. The construction type of the existing building was 'Wimpey-no fines', refereeing to a solid concrete wall construction that was common in the UK after the second world war. Due to shortage of skilled labour and the increased need for new housing, the construction industry was under pressure to find a solution that overcomes these conflicting constraints. The Wimpey construction was successful in addressing that problem, and some 300,000 houses were built in the late 1940s and early 1950s. The 'no-fines' part of the name of this construction refers to concrete without fine aggregates, such as sand.

The retrofit was carried out on the basis of 'TCosy' approach, in which the existing building is completely surrounded by a Passivhaus type of thermal envelope (Beattie, 2017). The building was extensively monitored before and after the retrofit. Data from a project weather station was used to synthesize the simulation weather data file used in this analysis.

The envelope characteristics before and after the retrofit are summarised in Table 1.
Table 1: Envelope characteristics before and after retrofit (Jankovic, 2018).

\begin{tabular}{|c|c|c|}
\hline \multirow{2}{*}{} & $\begin{array}{c}\text { Before } \\
\text { retrofit }\end{array}$ & $\begin{array}{c}\text { After } \\
\text { Retrofit }\end{array}$ \\
\cline { 2 - 3 } & \multicolumn{2}{|c|}{$\begin{array}{c}\text { U-value } \\
\mathrm{W} /\left(\mathrm{m}^{2} \mathrm{~K}\right)\end{array}$} \\
\hline External walls & 1.48 & 0.11 \\
\hline External glazing & 1.60 & 0.79 \\
\hline External door & 2.56 & 0.78 \\
\hline Ground floor slab & 1.49 & 0.26 \\
\hline Roof & 0.47 & 0.10 \\
\hline \hline House & \multicolumn{2}{|c|}{$\begin{array}{c}\text { Air tightness } \\
1 / \mathrm{h} \text { at 50 Pascal }\end{array}$} \\
\hline A & 6.05 & $\begin{array}{c}\text { calibrated } 0.8 \\
\text { measured } 1.78^{\S}\end{array}$ \\
\hline B & 10.74 & $\begin{array}{c}\text { calibrated } 0.8 \\
\text { measured } 1.78^{\S}\end{array}$ \\
\hline
\end{tabular}

${ }^{\S}$ Attempts to calibrate the model with fixed air tightness values obtained from a measurement by a third party resulted in calibration non-convergence, indicating a measurement error; instead, air tightness was set as a variable and a value obtained from the calibration was used.

The simulation model calibration was carried out before and after the retrofit, thus giving an accurate representation of the building in both phases. Dynamic heating test simulations were subsequently carried out for both phases, and the building time constant, effective thermal capacitance, and effective conductance-area product were obtained for the building before and after the retrofit.

The method introduced in this article represents a tool for establishing physics properties of buildings in use before and after retrofit, and facilitates quality control of retrofit projects.

The results of this research give new insights into the scale of differences between theoretical and actual building physics parameters before and after the retrofit, and raise important issues about the use of theoretical values of material properties by designers. Practical guidance for safety margins is provided on the basis of results of this research.

\section{Method}

When a building is subjected to a step heat input, its temperature changes exponentially, as shown in Figure 2.

The method for determining building thermal properties from dynamic tests is based on previously published and ongoing research (Jankovic, 1988, p. 95; Jankovic, 2017, p. 261). Thus, the change of internal temperature is defined as

$$
T_{t}=T_{\text {start }}+\left(T_{\text {max }}-T_{\text {start }}\right) \times\left(1-e^{-\left(\frac{t}{t_{c}}\right)}\right)
$$




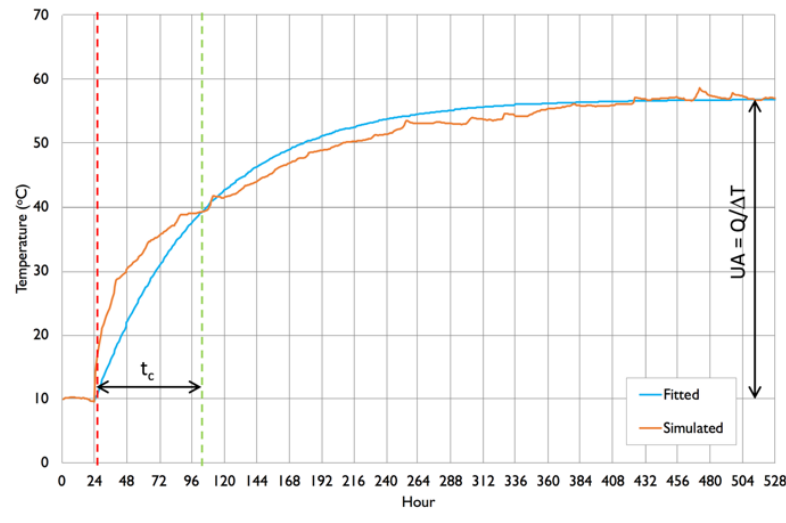

Figure 2: Dynamic heating test simulation.

Minimisation of root mean squared error (RMSE), defined with Equation (2), is carried out using the differences between simulated temperatures and temperatures calculated from Equation (1) on an hourly basis. The time constant $t_{c}$ is then obtained as a direct result of the RMSE minimisation. The minimisation in this particular case was carried out using Microsoft Excel Data Solver.

$$
R M S E=\sqrt{\frac{\sum_{1}^{n}\left(T_{r}-T_{t}\right)^{2}}{n}}
$$

Subsequently, the overall transmittance-area product is obtained from the steady-state part of the dynamic test as follows:

$$
U A=\frac{Q}{T_{r}-T_{o}}
$$

As the time constant $t_{c}$ and the overall conductance-area product $U A$ are now known, that enables the calculation of the effective thermal capacitance $C$ as follows:

$$
C=t_{c} \times U A
$$

In order to implement the above calculations, the simulation model needs to be calibrated using data from monitoring.

The simulation model was developed in EnergyPlus, and the model calibration was carried out using parametric simulation and multi-objective optimisation in JEA, (Zhang \& Jankovic, 2017) which uses EnergyPlus as its underlying simulation engine. The parameters varied were: wall and roof constructions; windows constructions; infiltration rates; heating set temperatures; lighting power density; and miscellaneous gains power density. The ranges for these parameters were chosen wide enough below and above the respective design values, and the steps of parameter changes were chosen to be sufficiently small to detect discrepancies from design values. The objective functions were specified to represent the absolute value of relative error between simulated and measured energy performance as follows:

$$
\varepsilon=\frac{\left|\left(E_{\text {measured }}-E_{\text {simulated }}\right)\right|}{E_{\text {measured }}}
$$

Each energy source, gas and electricity, was assigned such objective function. Thus, gas energy consumption calibration was carried out by varying wall, roof and window constructions; infiltration rates; and heating set temperatures; and minimising the error between measured and simulated gas consumption. Electricity energy consumption calibration was carried out by varying the lighting power density and miscellaneous gains power density and minimising the error between measured and simulated electricity consumption. The minimisation of errors was achieved through multi-objective optimisation using NSGA-II algorithm (Deb et al., 2002).

The calibration process is illustrated in Figure 3, where the arrow points to the minimum errors in respect of electricity and gas consumption. The parameters of the simulation model that resulted in the minimum errors for each are shown in the yellow rectangle in this figure, and are taken forward into the simulation model to be used for dynamic tests.

Model calibration was carried out for both pre-retrofit and post-retrofit cases, and the results of calibration will be shown in the next section, together with the results of dynamic tests.

The calibrated model, together with the method described above now enables a practical calculation of the building thermal properties through dynamic heating tests, and a comparison with theoretical values of these properties obtained from manufacturers' specifications.

\section{Results}

The results of calibration of the models before and after retrofit are shown in Figure 4. The high accuracy of these models, as evidenced from the table, justified their use for conducting dynamic heating tests.

Prior to the tests, the models were adjusted so that all internal heat gains were switched off. The model preconditioning period was set to zero days, and a heat input schedule was created to start the heating after the first 24 hours of the simulation and to keep it on until the end of simulation.

Table 2: Model calibration results.

\begin{tabular}{|l|r|r|}
\hline Description & $\begin{array}{c}\text { Before } \\
\text { retrofit }\end{array}$ & $\begin{array}{c}\text { After } \\
\text { retrofit }\end{array}$ \\
\hline Gas consumption error & $0.33 \%$ & $0.42 \%$ \\
\hline Model accuracy - gas consumption & $99.67 \%$ & $99.58 \%$ \\
\hline Electricity consumption error & $0.17 \%$ & $0.05 \%$ \\
\hline $\begin{array}{l}\text { Model accuracy - electricity } \\
\text { consumption }\end{array}$ & $99.83 \%$ & $99.95 \%$ \\
\hline
\end{tabular}

The results of a set of tests with $8 \mathrm{~kW}$ input are shown in Figure 4. Both pre-retrofit and post-retrofit cases are shown, as pairs of simulated and fitted curves. The curve fitting was based on Equations (1) and (2), and the building time constant $t_{c}$ was obtained from this process. 




Figure 3: Simulation model calibration.

The calculation of the overall transmittance-area product $U A$ and of the effective thermal capacitance $C$ was then carried out on the basis of Equations (3) and (4).



Figure 4: Dynamic heating test results with $8 \mathrm{~kW}$ heat input.

The first observation that can be made from Figure 4 is that in the pre-retrofit case the final balance temperature of $26^{\circ} \mathrm{C}$ was significantly lower than in the post-retrofit case of $57^{\circ} \mathrm{C}$. As both tests were run with $8 \mathrm{~kW}$ input using the same weather data file over the same period, the differences of balance temperatures were attributed to different heat loss rates in the two cases.
The results of building physics parameters obtained from dynamic tests are summarised in Table 3.

Table 3: Building physics parameters obtained from 8 $k W$ dynamic tests.

\begin{tabular}{|l|r|r|r|}
\hline & \multicolumn{1}{|c|}{$\begin{array}{c}\text { Post- } \\
\text { retrofit }\end{array}$} & \multicolumn{1}{c|}{$\begin{array}{c}\text { Pre- } \\
\text { retrofit }\end{array}$} & $\begin{array}{c}\text { Ratio Post- } \\
\text { retrofit/Pre } \\
\text {-retrofit }\end{array}$ \\
\hline $\mathrm{t}_{\mathrm{c}}(\mathrm{h})$ & 80.69 & 19.83 & 4.07 \\
\hline $\mathrm{UA}(\mathrm{W} / \mathrm{K})$ & 157.69 & 356.65 & 0.44 \\
\hline $\mathrm{C}(\mathrm{MJ} / \mathrm{K})$ & 45.81 & 25.47 & 1.80 \\
\hline $\mathrm{U}\left(\mathrm{W} / \mathrm{m}^{2} \mathrm{~K}\right)$ & 0.74 & 1.73 & 0.43 \\
\hline
\end{tabular}

The initial observations from Figure 4 can now be elaborated upon using the numerical results from Table 3 . As the UA value in the post-retrofit case is only 0.44 of the UA value in the pre-retrofit case, that explains the final balance temperatures of $57{ }^{\circ} \mathrm{C}$ and $26{ }^{\circ} \mathrm{C}$ reached with $8 \mathrm{~kW}$ input in both cases.

The time constant of 19.8 hours before the retrofit is significantly shorter than the time constant of 80.7 hours after the retrofit. The practical implication of this finding is that the post-retrofit case is about four times slower in responding to heat input, which means that it delivers more stable internal temperatures. This will have 
implications on higher thermal comfort and lower heating energy consumption.

Table 4: Pre-retrofit tests with varying heat input.

\begin{tabular}{|c|c|c|c|c|c|}
\hline $\begin{array}{l}\text { Heat } \\
\text { input }\end{array}$ & $3 \mathbf{k W}$ & $6 \mathrm{~kW}$ & $9 \mathrm{~kW}$ & Mean &  \\
\hline $\begin{array}{l}\text { tc } \\
\text { (h) }\end{array}$ & 25.57 & 20.90 & 19.33 & 21.93 & 2.65 \\
\hline $\begin{array}{c}\mathrm{UA} \\
(\mathrm{W} / \mathrm{K})\end{array}$ & 284.17 & 338.66 & 363.28 & 328.70 & 33.05 \\
\hline $\begin{array}{c}\mathrm{C} \\
(\mathrm{MJ} / \mathrm{K})\end{array}$ & 26.16 & 25.48 & 25.27 & 25.64 & 0.38 \\
\hline $\begin{array}{c}\mathrm{U} \\
\left(\mathrm{W} / \mathrm{m}^{2} \mathrm{~K}\right)\end{array}$ & 1.33 & 1.58 & 1.70 & 1.54 & 0.15 \\
\hline
\end{tabular}

Table 5: Post-retrofit tests with varying heat input.

\begin{tabular}{|c|c|c|c|c|c|}
\hline $\begin{array}{l}\text { Heat } \\
\text { input }\end{array}$ & $3 \mathrm{~kW}$ & $6 \mathrm{~kW}$ & $9 \mathrm{~kW}$ & Mean & 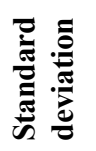 \\
\hline $\begin{array}{c}t_{c} \\
(h)\end{array}$ & 77.11 & 80.33 & 77.72 & 78.39 & 1.40 \\
\hline $\begin{array}{c}\text { UA } \\
(\mathrm{W} / \mathrm{K})\end{array}$ & 130.59 & 150.64 & 160.71 & 147.32 & 12.52 \\
\hline $\begin{array}{c}\mathrm{C} \\
(\mathrm{MJ} / \mathrm{K})\end{array}$ & 36.25 & 43.56 & 44.97 & 41.59 & 3.82 \\
\hline $\begin{array}{c}\mathrm{U} \\
\left(\mathrm{W} / \mathrm{m}^{2} \mathrm{~K}\right)\end{array}$ & 0.61 & 0.70 & 0.75 & 0.69 & 0.06 \\
\hline
\end{tabular}

However, the four times higher time constant will not contribute to four times lower energy consumption. Energy consumption improvements cannot be solely determined on the basis of the relationship between individual physics parameters, including the UA values before and after the retrofit. Thus, heating energy consumption after retrofit will not be a direct reflection of the reduction of the UA value of $66 \%$, as derived from Table 3. This is because the reduction of the heating energy consumption will be the consequence of a combination of all building physics properties, including the UA value, the time constant, and the effective thermal capacitance.

The correct way to determine the energy savings from this analysis is to run the simulations with the calibrated models, and to normalise the results to long term weather changes. This will be revisited later in this section.

However, before calculating heating energy savings, we wanted to investigate whether the same results of building physics parameters would be obtained with different heat input rates during dynamic heating test simulations. The tests were therefore repeated with $3 \mathrm{~kW}, 6 \mathrm{~kW}$ and $9 \mathrm{~kW}$. The results for the pre-retrofit case are shown in Table 4, and for the post-retrofit case in Table 5.

The post-retrofit and pre-retrofit cases can now be compared more generally, as shown in Table 6.

Table 4 and Table 5 show that different heat inputs resulted in different values of building physics parameters, while similar temperature change pattern was observed as in Figure 4. Can therefore the building physics be different just on the basis of different heat inputs? Definitely not, as fundamental properties of building materials could not have changed just on the basis of different heat input, and there were no phase change materials that could have, for instance, changed the thermal storage properties. The explanation lies in the precursor to this analysis, where parametric simulation and multi-objective optimisation were used to calibrate the simulation models.

Table 6: Comparison of results with varying heat input.

\begin{tabular}{|c|c|c|c|c|c|}
\hline &  & 连 & 窇 & 咅 & 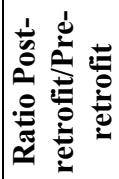 \\
\hline $\begin{array}{l}\text { tc } \\
(\mathrm{h})\end{array}$ & 78.39 & 1.40 & 21.93 & 2.65 & 3.57 \\
\hline $\begin{array}{c}\mathrm{UA} \\
(\mathrm{W} / \mathrm{K})\end{array}$ & 147.32 & 12.52 & 328.70 & 33.05 & 0.45 \\
\hline $\begin{array}{c}\mathrm{C} \\
(\mathrm{MJ} / \mathrm{K})\end{array}$ & 41.59 & 3.82 & 25.64 & 0.38 & 1.62 \\
\hline $\begin{array}{c}\mathrm{U} \\
\left(\mathrm{W} / \mathrm{m}^{2} \mathrm{~K}\right)\end{array}$ & 0.69 & & 1.54 & & 0.45 \\
\hline
\end{tabular}

As the simulation models were calibrated using measured data, there is a measurement error embedded in the results of dynamic heating test simulations. The correct way of calculating the results is therefore to carry out several simulations and express the results as mean value \pm standard deviation.

Therefore, when expressed in this more general way, the results of dynamic heating test simulations can be compared with theoretical U-values. Thus, both theoretical and measured values are shown in Table 7.

Table 7: Theoretical and measured UA values.

\begin{tabular}{|c|c|c|}
\hline Description & Post-retrofit & Pre-retrofit \\
\hline $\begin{array}{c}\text { Theoretical UA value } \\
\text { (W/K) }\end{array}$ & 97.89 & 318.56 \\
\hline $\begin{array}{c}\text { UA value obtained from } \\
\text { simulated dynamic heating } \\
\text { tests (W/K) }\end{array}$ & $147.32 \pm$ & $328.70 \pm$ \\
& 12.52 & 33.05 \\
\hline
\end{tabular}

The theoretical UA values in this table were adjusted taking the influence of infiltration/ventilation and thermal bridging into account (UAtheoretical $=\Sigma U_{i} A_{i}+N V / 3+\Sigma$ $L_{j} \psi_{j}$ ), in order to make a fair comparison with the measured UA values obtained from simulated dynamic heating tests. As air tightness figures relate to test conditions of $50 \mathrm{~Pa}$ in Table 1, these figures were proportionally scaled down from $50 \mathrm{~Pa}$ to the expected 3 $\mathrm{Pa}$ under normal operational conditions, before calculating these theoretical values.

The results from Table 7 can be unpacked in terms of lower and higher end values, by either subtracting or 
adding the standard deviation to the mean value, as shown in Table 8.

Table 8: Comparison between theoretical and measured $U A$ values.

\begin{tabular}{|c|c|c|}
\hline & $\begin{array}{c}\text { Post- } \\
\text { retrofit }\end{array}$ & $\begin{array}{c}\text { Pre- } \\
\text { retrofit }\end{array}$ \\
\hline Theoretical UA value $(\mathrm{W} / \mathrm{K})$ & 97.89 & 318.56 \\
\hline \multicolumn{3}{|c|}{ Measured values from simulated dynamic heating tests } \\
\hline Lower end of range $(\mathrm{W} / \mathrm{K})$ & 134.79 & 295.65 \\
\hline Higher end of range $(\mathrm{W} / \mathrm{K})$ & 159.84 & 361.75 \\
\hline Average $(\mathrm{W} / \mathrm{K})$ & 147.32 & 328.70 \\
\hline \multicolumn{3}{|c|}{ discrepancy $=($ measured - theoretical $) /$ theoretical } \\
\hline Lower end of range $(\%)$ & $38 \%$ & $-7 \%$ \\
\hline Higher end of range $(\%)$ & $63 \%$ & $14 \%$ \\
\hline Average (\%) & $50 \%$ & $3 \%$ \\
\hline
\end{tabular}

Table 9 Energy consumption normalisation factors

\begin{tabular}{|c|c|c|}
\hline \multicolumn{2}{|c|}{$\begin{array}{c}\text { Degree Days calculation } \\
\text { (base temperature } 15.5 \mathrm{oC} \text { ) }\end{array}$} & $\begin{array}{c}\text { Energy } \\
\text { consumption } \\
\text { normalisation }\end{array}$ \\
\hline $\begin{array}{l}\text { Post retrofit (source: } \\
\text { monitoring system weather } \\
\text { station) }\end{array}$ & 1826 & 1.00 \\
\hline $\begin{array}{l}\text { Pre-retrofit (source: weather } \\
\text { file } \\
\text { GBR_Birmingham.035340_I } \\
\text { WEC.EPW) }\end{array}$ & 2300 & 1.26 \\
\hline $\begin{array}{l}\text { Pre-retrofit (source: CIBSE } \\
\text { for Birmingham-Elmdon) }\end{array}$ & 2425 & 1.33 \\
\hline
\end{tabular}

These results will be discussed in the next section. Going back to the calculation of heating energy savings, referred to earlier in the text, we first need to calculate weather normalisation factors from Degree Days, as shown in Table 9, and apply these factors to simulated energy consumption figures with the calibrated models, as shown in Table 10.

Table 10: Long term energy consumption calculations.

\begin{tabular}{|c|c|c|c|c|c|}
\hline & 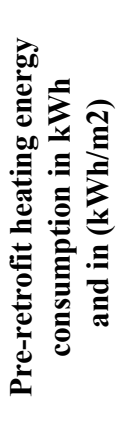 & 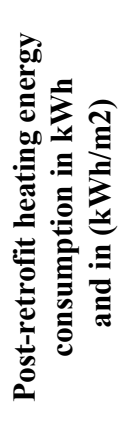 &  & 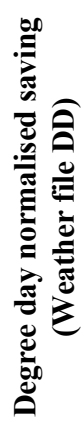 &  \\
\hline $\begin{array}{l}\text { Including } \\
\text { base load }\end{array}$ & $\begin{array}{l}12179 \\
(162)\end{array}$ & $\begin{array}{l}5699 \\
(76)\end{array}$ & $53 \%$ & $41 \%$ & $38 \%$ \\
\hline $\begin{array}{l}\text { Excluding } \\
\text { base load }\end{array}$ & $\begin{array}{l}11511 \\
(153)\end{array}$ & $\begin{array}{l}5032 \\
(67)\end{array}$ & $56 \%$ & $45 \%$ & $42 \%$ \\
\hline
\end{tabular}

As it can be seen from Table 10, the lowest energy consumption savings are $38 \%$ including the base load, or
$42 \%$ excluding the base load. The base load was established as gas energy consumption during summer months when heating was not in operation, and it was attributed to energy used for cooking and domestic hot water. These could not have been anticipated from the individual physics parameters alone, due to a combined influence of these parameters on the dynamics of heat transfer.

\section{Discussion}

As it can be seen from the Results section, there are significant discrepancies between the theoretical and measured UA values. These go as high as $14 \%$ in the preretrofit case and as high as $63 \%$ in the post-retrofit case. These discrepancies are one of the factors that contribute to the performance gap between design simulations and building performance in use.

How can these discrepancies be addressed? Technical specifications of building materials need to be reevaluated systematically and new guidance for designers needs to be published by professional organisations such as CIBSE and ASHRAE. Before such new technical guidance becomes available, a significant safety margin in terms of building material properties could be deployed by designers. That safety margin could be as high as the discrepancies found in this research.

The results show that surrounding a solid concrete building with a new thermal envelope increases its time constant. This is especially evident in Table 6 , from where it can be seen that the time constant has increased 3.57 times as result of retrofit. Considering that no high density material was added to the building through retrofit but only lightweight thermal insulation, the increase of time constant could be counterintuitive. However, this is consistent with the definition: "Thermal mass is a relationship between the building thermal capacitance $C$ and the overall transmittance-area product UA of the building, which through the time constant $t_{c}$ gives information on the speed of response of a building to a heat input." (Jankovic, 2017, p. 130). Therefore, thermal mass is not just the high density material in the building, but a combination of that material and the surrounding thermal insulation. This is evident from Equation (4), where a reduced $U A$ value resulting from retrofitting thermal insulation on a building with a constant thermal capacitance $C$ will result in an increase of the time constant $t_{c}$.

What is the meaning of the increased time constant? The building will be slower to respond to heat gains and losses. It will heat up more slowly and it will cool down more slowly. Building occupants will therefore experience more gradual temperature changes, and the resultant thermal comfort will be better.

Table 6 also shows 1.62 times increase in the effective thermal capacitance $C$. As no high density materials were added to the building through retrofit, the scale of increase is unexpected. This could be attributed to the timber frame construction of the external envelope panels (Figure 5), where the timber most likely contributed to the increase of effective thermal capacitance. 


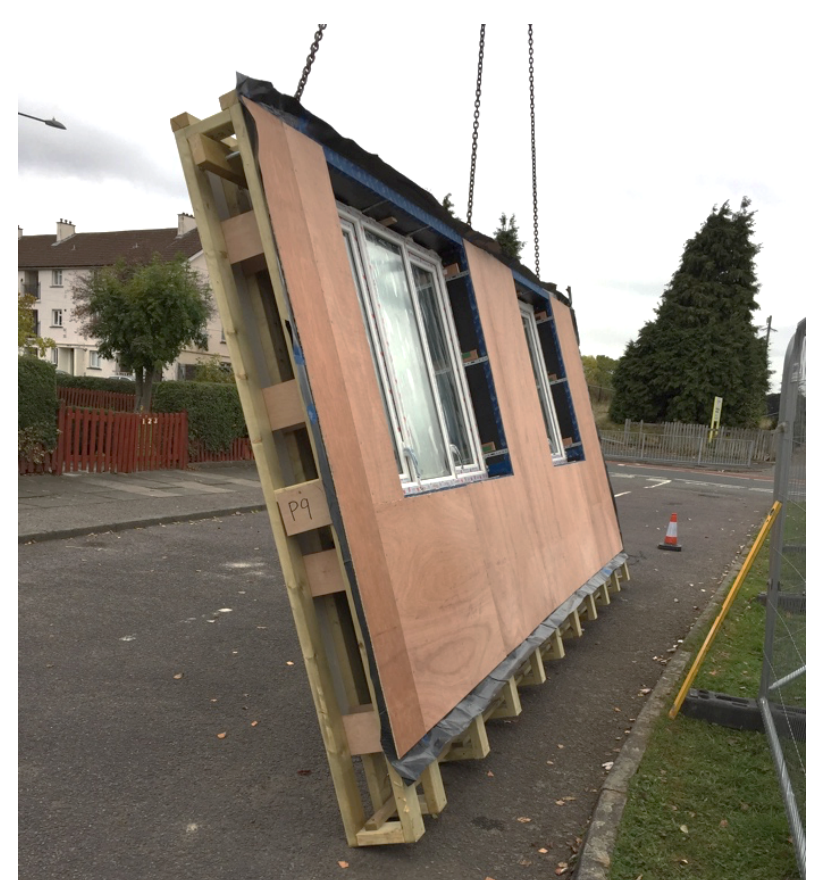

Figure 5: External insulation panel built from timber frame, before installation and insulation injection.

Alternatively, this could be attributed to a combined effect of multiple variables used in the calibration process. Whilst the accuracy of the calibrated models before and after retrofit was exceptionally high as shown in Table 2, this could have been a consequence of a 'cocktail' effect of multiple parameters acting simultaneously.

This means that different parameters, such as time constant and effective thermal capacitance, could have both been changed as result of multi-objective optimisation, but in reality, only one could have changed and the other could have remained constant. They could be 'two sides of the same coin' and to be collectively holding information on the dynamics of building heat transfer.

This is one of the reasons why energy savings through retrofit cannot be evaluated on the basis of changes of the individual physics parameters alone. Another reason is, as already stated in the Results section, that UA value reduction is not directly proportional to energy savings, without also taking into account heat transfer dynamics effects represented by the time constant and effective thermal capacitance. Thus, energy savings need to be evaluated through dynamic simulation with the calibrated models, rather than on the basis of changes of the individual building physics properties alone.

Initially, it was somewhat surprising that dynamic heating test simulations with different rates of heat input produced different values of building physics parameters. As there were no phase change materials in the building, and as there were no other reasons for alterations of heat related physics properties, an explanation for these differences was sought in the steps preceding the simulations of dynamic heating tests. The simulation models were calibrated prior to conducting the tests, in order to achieve accurate representations of the building before and after retrofit. The calibration used data from monitoring, and the calibrated models therefore had become a measurement instrument that carried forward the measurement errors. The resolution of these differences was a realisation that a dynamic test with a single heat input rate is not sufficient to obtain results. Several tests need to be carried out with different heat input rates, and the results need to be expressed in the same way as results of other measurements, namely as mean value \pm standard deviation.

Despite of the uncertainties introduced in this section, the method of measuring building physics properties represents a useful tool to ensure that design performance specification is correctly implemented.

\section{Conclusion}

The current practice of building design simulations is to use theoretical properties of materials, either built into the simulation tools, or obtained from manufacturers' specifications or from technical reference tables. These properties are rarely compared to actual properties of buildings in use. That leads to a performance gap between design simulations and actual performance of the constructed building. This is significant in deep energy retrofit projects, where it is important to know the properties of the existing building to be retrofitted, and of the materials to be retrofitted, in order to be able to design with confidence.

Building physics properties can be obtained from physical tests, such as co-heating tests or dynamic heating tests, but these tests are impractical, as they require the building to be unoccupied, during a period of stable winter weather. The use of additional heaters required to carry out these tests could result in cracks in the building materials due to differential thermal expansion rates caused by higher than usual internal temperatures.

This research introduces an alternative method for obtaining building physics properties through simulation of dynamic heating tests using calibrated simulation models. It uses a real deep energy retrofit project as evidence base, which was monitored extensively before and after the retrofit. The calibration is based on data obtained from ongoing monitoring during normal use of the building.

In seeking to answer a practical question on how to assess whether U-values of the components of external envelope are equal to or higher than those in manufacturers' specifications, this research has made two lasting contributions. First, the method introduced in this article represents a tool for establishing physics properties of buildings in use before and after retrofit, and facilitates quality control of retrofit projects. Second, this research raises the awareness of the discrepancies between theoretical and actual building material properties, and calls for re-evaluation of technical guidance for designers. Considering that the highest discrepancy calculated was $63 \%$, commensurable safety margins need to be implemented in design projects. 


\section{Nomenclature}

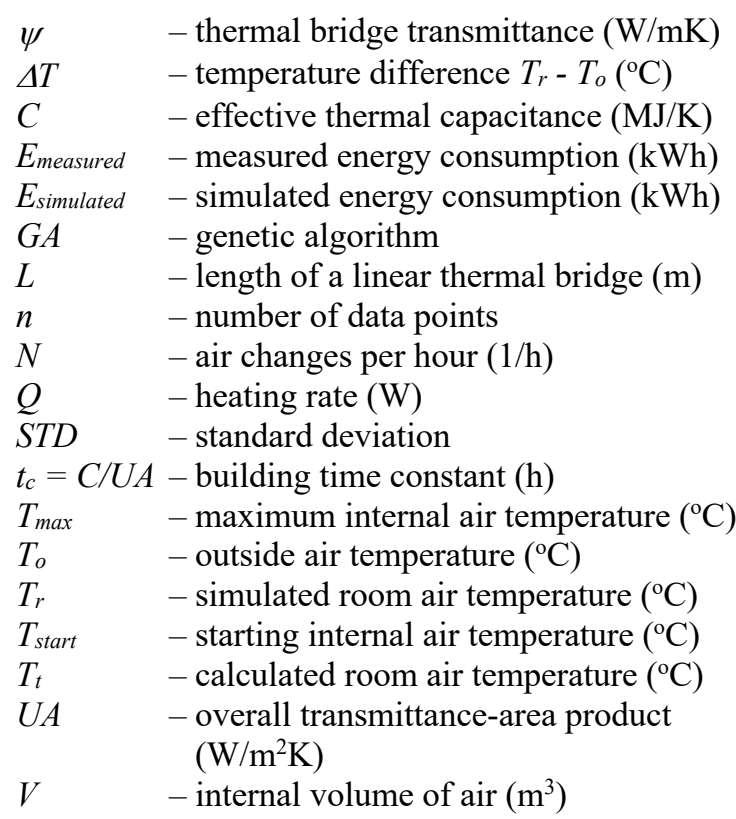

\section{Acknowledgements}

The deep energy retrofit project called Retrofit Plus referred to in this article was part-funded by Innovate UK grant reference number 101614 and matched by funding from Retrofit Plus Project Consortium: Beattie Passive Retrofit Ltd, iZdesign Ltd, and InteSys Ltd, and with Birmingham City University as academic partner. The support from Birmingham City Council for providing the buildings to retrofit is gratefully acknowledged.

\section{References}

Abushakra, B. (1997). An Inverse Model to Predict and Evaluate the Energy Performance of Large Commercial and Institutional Buildings. Proceedings of Building Simulation 1997, 8.

Beattie, R. (2017). TCosy ${ }^{\mathrm{TM}}$ - Transforming homes, Improving Lifestyles. http://www.beattiepassiveretrofit.com/

Deb, K., Pratap, A., Agarwal, S., \& Meyarivan, T. (2002). A fast and elitist multiobjective genetic algorithm: NSGA-II. IEEE Transactions on Evolutionary
Computation,

$6(2)$

$182-197$.

https://doi.org/10.1109/4235.996017

Jankovic, L. (1988). Solar Energy Monitoring, Control and Analysis in Buildings [PhD Thesis]. University of Birmingham.

Jankovic, L. (2017). Designing Zero Carbon Buildings Using Dynamic Simulation Methods (2nd ed.). Routledge.

Jankovic, L. (2018). Designing Resilience of the Built Environment to Extreme Weather Events. Sustainability, $10(1)$. https://doi.org/10.3390/su10010141

Jankovic, L., \& Basurra, S. (2016). Taking a Passivhaus certified retrofit system onto scaled-up zero carbon trajectory. In Proceedings of Zero Carbon Buildings Today and in the Future. Birmingham City University.

http://www.zerocarbonbuildings.world/2016/proceed ings.html

Ramos Ruiz, G., Fernández Bandera, C., Gómez-Acebo Temes, T., \& Sánchez-Ostiz Gutierrez, A. (2016). Genetic algorithm for building envelope calibration. Applied Energy, 168, 691-705. https://doi.org/10.1016/j.apenergy.2016.01.075

Rezaee, R., Brown, J., Haymaker, J., \& Augenbroe, G. (2019). A new approach to performance-based building design exploration using linear inverse modeling. Journal of Building Performance Simulation, 12(3), 246-271. https://doi.org/10.1080/19401493.2018.1507046

Zhang, Y., \& Jankovic, L. (2017). JEA, An Interactive Optimisation Engine for Building Energy Performance Simulation. Proceedings of BS 2017: 15th Conference of the International Building Performance Simulation Association.

Zhang, Yuna, O’Neill, Z., Dong, B., \& Augenbroe, G. (2015). Comparisons of inverse modeling approaches for predicting building energy performance. Building and Environment, 86, 177-190. https://doi.org/10.1016/j.buildenv.2014.12.023 